\title{
Quality of life and its association with current substance use, medication non- adherence and clinical factors of people with schizophrenia in Southwest Ethiopia: a hospital-based cross-sectional study
}

Defaru Desalegn', Shimelis Girma ${ }^{2}$ and Tilahun Abdeta ${ }^{3^{*}}$

\begin{abstract}
Background: Schizophrenia was ranked as one of the top ten illnesses contributing to the global burden of disease. But little is known about the quality of life among people with schizophrenia, in particular in low-income countries. This study was aimed to examine the association of quality of life with current substance use, medication non-adherence and clinical factors of people with schizophrenia at Jimma University Medical Center, psychiatry clinic, Southwest Ethiopia.

Methods: Institution based cross-sectional study design was employed. Study participants were recruited using a systematic random sampling method and a sample fraction of two was used after the first person was identified by the lottery method. we used the World Health Organization Quality of Life Scale-Brief version (WHOQoL-BREF) and 4-item Morisky Medication Adherence Scale (MMAS-4) to assess the quality of life and medication non-adherence respectively. Data about current substance use was assessed by yes/no questions. Descriptive statistics, such as frequency, mean and standard deviations were computed to describe the characteristics of the study population. Data entry was done using EpiData version 3.1 then exported to SPSS statistics version 25 for analysis and analyzed using multiple linear regression. The assumption for linear regression analysis including the presence of a linear relationship between the outcome and predictor variable, the test of normality, collinearity statistics, auto-correlation and homoscedasticity were checked. Unstandardized Beta ( $\beta$ ) coefficients with 95\% confidence interval (Cl) and $P$-value $<0.05$ were computed to assess the level of association and statistical significance in the final multiple linear regression analysis.

(Continued on next page)
\end{abstract}

\footnotetext{
* Correspondence: tilahunabdeta@gmail.com

${ }^{3}$ Department of Psychiatry, college of health and medical sciences, School of Nursing and Midwifery, Haramaya University, Harar, Ethiopia

Full list of author information is available at the end of the article
}

(c) The Author(s). 2020 Open Access This article is licensed under a Creative Commons Attribution 4.0 International License, which permits use, sharing, adaptation, distribution and reproduction in any medium or format, as long as you give appropriate credit to the original author(s) and the source, provide a link to the Creative Commons licence, and indicate if changes were made. The images or other third party material in this article are included in the article's Creative Commons licence, unless indicated otherwise in a credit line to the material. If material is not included in the article's Creative Commons licence and your intended use is not permitted by statutory regulation or exceeds the permitted use, you will need to obtain permission directly from the copyright holder. To view a copy of this licence, visit http://creativecommons.org/licenses/by/4.0/. The Creative Commons Public Domain Dedication waiver (http://creativecommons.org/publicdomain/zero/1.0/) applies to the data made available in this article, unless otherwise stated in a credit line to the data. 


\begin{abstract}
(Continued from previous page)
Result: In this study $31.65 \%$ of participants were medication non-adherent and total mean scores of quality of life showed a lower level of satisfaction in social relationship domain (10.14 \pm 3.12$)$. Our study showed 152(43.3\%), 248(70.7\%) and $97(27.6 \%)$ of respondents had used tobacco, Khat and alcohol atleast once during the past 3 months respectively. Final adjusted multiple regression model showed medication non-adherence has significant negative association with physical domain (beta $=-4.42, p<0.001$ ), psychological (beta $=-4.49, p<0.001$ ), social relationships (beta $=-2.29, p<$ 0.001 ) and environmental domains (beta $=-4.95, p<0.001$ ). Treatment duration has significant negative association with psychological domain (beta $=-0.17, p<0.04$ ), social relationship (beta $=-0.14, p<0.005)$, environmental domain (beta $=$ $-0.24, p<0.02$ ) and overall quality of life (beta $=-0.67, p<0.02$ ). Having comorbid physical illness has significant negative association with physical domain (beta $=-2.74, p<0.001$ ), psychological (beta $=-2.13, p<0.004$ ), social relationships (beta $=-1.25, p<0.007$ ), environmental domain (beta $=-3.39, p<0.001$ ) and overall quality of life (beta $=-$ $9.9, p<0.001$ ). Current tobacco use has significant negative association with physical domain (beta $=-1.16, p<0.004$ ), psychological (beta $=-1.23, p<0.001$ ), social relationships (beta $=-0.88, p<0.001$ ), environmental domains (beta $=-$ $1.98, p<0.001$ ) and overall quality of life (beta $=-5.73, p<0.001$ ). Also, current chewing khat has significant negative association with physical domain (beta $=-1.15, p<0.003$ ), psychological (beta $=-1.58, p<0.001$ ), environmental domains (beta $=-2.63, p<0.001$ ) and overall quality of life (beta $=-6.22, p<0.001$ ).

Conclusion: The social relationship domain of quality of life has the lowest mean score. Medication non-adherence, treatment duration, having a comorbid physical illness, current tobacco use and current chewing khat were found to have a statistically significant association with the overall quality of life. Therefore, treatments aimed to improve social deficits, medication non-adherence, comorbid physical illness and decrease substance abuse is imperative.
\end{abstract}

Keywords: Quality of life, Medication non-adherence, Current substance use, Clinical factors, Schizophrenia, Ethiopia

\section{Background}

Schizophrenia is one of the most severe, chronic and disabling mental disorders [1]. It affects general health, functioning, autonomy, subjective wellbeing, and alters individuals' perception of reality [2]. Globally, as estimated by the World Health Organization (WHO), about 24 million people suffer from schizophrenia [3]. It was ranked as one of the top ten illnesses contributing to the global burden of disease [4]. In developing countries, around $90 \%$ of people with schizophrenia remain untreated [5]. In Ethiopia, mental illness is the leading non-communicable disease in terms of burden. Indeed, in a predominantly rural area of Ethiopia, mental illness comprised $11 \%$ of the total burden of disease, with schizophrenia and depression included in the top ten most burdens [6].

Schizophrenia affects many areas of functioning. People with the illness often lead an isolated and marginalized existence in poor housing, with a low income, little education, and poor vocational and social skills [2]. Most individuals are employed at a lower level and the majority of them have limited social contacts outside of their family [7]. People with schizophrenia are also prone to stigma, which leads to discrimination and thus affects their life opportunities and quality of life (QoL) [8].

Quality of life in individuals with schizophrenia has been measured from both subjective and objective points of view. Subjective measures of QoL include general indicators of life satisfaction and several life domains such as satisfaction with work, family, social relations, finances, and housing situations. The objective measures of QoL usually include indicators of external life conditions, socio-demographic items, and a functioning role in society [9]. However, the World Health Organization (WHO) focused on the subjective aspect and defines the quality of life as individuals' perception of their position in life in the context of the culture and value systems concerning their goals, expectations, standards, and concerns [10].

A study done in China found that people with schizophrenia who were treated in primary care had a lower level of QoL when compared to the general population [11]. A cross-sectional comparative study done in Pakistan showed that people with schizophrenia had significantly poorer quality of life when compared with healthy subjects [12] and also they have worse than that of other physically ill people [13]. A study conducted in Bangladesh found out, most of the schizophrenic patient lead poor to moderate quality of life in four domains of the World Health Organization Quality of Life Scale Brief Version (WHOQOL-BREF scale) [14].

Quality of life of patients with schizophrenia can be affected by different factors including socio-demographic variables, type of psychopathology $[15,16]$, social support and substance use disorders [17]. A study done in Spain among people with schizophrenia found that young people, women, married persons, and those with a low level of education report better quality of life [13]. Also, a study from Jordan reveals that QoL of people with schizophrenia was correlated positively with social 
support, individuals' educational, income level, and employment [16]. But, one study done in Sweden showed that the socio-demographic indicators have a weak influence on the patient's self-assessed quality of life [18].

Several studies have evaluated the associations between quality of life and clinical factors among individuals with schizophrenia. As a study done in Jordan, QoL of people with schizophrenia was correlated negatively with the severity of psychiatric symptoms, duration of untreated illness and duration of treatment [16]. Thus, the longer the length of the illness is associated with the worse the quality of life of people with schizophrenia [13].

A one-year randomized clinical trial (RCT) study done in the United Kingdom (UK) among 363 people with schizophrenia has indicated as improved adherence to medication leads to improved QoL [19]. As a study done in Nigeria among 313 people with schizophrenia attending outpatient treatments, $40.3 \%$ of the respondents were medication non-adherent and respondents with poor medication adherence had lower scores on all domains of quality of life and the facets of Overall QoL and General Health compared with medication-adherent subjects [20]. Also, another study done in Nigeria found that there are significant negative correlations between the overall health satisfaction, physical and psychological domains of quality of life and medication adherence: i.e. participants with poorer medication adherence were more likely to have poorer mean scores on the overall QoL, health satisfaction, physical and psychological domains [21].

Another factor that affects the quality of life of patients with schizophrenia is substance use status. According to one study conducted in Turkey among patients dually diagnosed with schizophrenia and substance use disorders and in non-substance-using male schizophrenia outpatients, there are significantly lower QoL scores in the comorbid group, specifically in the psychological domain of WHOQOL-BREF [17]. Contrary to this, dual-diagnosed patients with schizophrenia and substance use in the study from Australia expressed higher levels of satisfaction with their QoL compared with non- comorbid patients [22].

Assessing the determinant factors of quality of life of people with schizophrenia is particularly important to minimize the impact of the disorder and to improve their quality of life. In Ethiopia, only limited national wide studies conducted on the quality of life and associated factors among people with schizophrenia and especially there was no study addressed the association of medication non-adherence and current substance use with quality of life and again no study conducted specifically in the study area. Therefore, this study aimed to examine the quality of life and its association with current substance use, medication non-adherence and clinical factors of people with schizophrenia and attending follow up service at Jimma University Medical Center, psychiatry clinic, Southwest Ethiopia.

\section{Materials and methods Study setting}

We conducted this study from April 15-June 15, 2018, among people with schizophrenia and attending, follow up service at Jimma University Medical Center (JUMC), psychiatry clinic, Southwest Ethiopia. Jimma University Medical Center is one of the oldest governmental hospitals, established in 1937 during the Italian occupation for the service of their soldiers [23]. The psychiatric clinic of JUMC was established in 1988 and gives clinical service for about 15 million population with a total of 40 beds for in-patient service and seven rooms for Out Patient Department (OPD) in Southwest Ethiopia during the study time [23]. Currently, there are more than 1000 people with schizophrenia who are attending follow up treatments at OPD monthly and on average, about 50 individuals with different mental illnesses are visiting psychiatric clinics daily.

\section{Study design and participants}

The hospital-based cross-sectional study design was conducted among people with schizophrenia and who were attending follow up service at Jimma University Medical Center, psychiatric clinic from April 15-June 15, 2018. Three hundred fifty-one adult persons (age 18 and above) who were diagnosed as schizophrenia according to the diagnostic criteria of the Diagnostic Statistical Manual (DSM-IV/V) by psychiatrists or by psychiatric nurses under the consultation of psychiatrists were included in the study. People whose acute episode symptoms pose difficulty to communicate were excluded from the study.

\section{Sample size determination and sampling technique}

The minimum sample size required for this study was determined by using the formula to estimate single population mean; using the assumptions of margin of error (d) 1; standard deviation of mean quality of life score 9.13 as reported by previous related study [18]; Z value at $(\infty=0.05)$ to be 1.96 and adding $10 \%$ nonresponse rate. Thus, the total sample size was 352 . Study participants were recruited by using a systematic random sampling method and a sample fraction of two was used after the first person was identified by using the lottery method. To avoid repeated inclusion of a patient into the study unique patient identification card number was used as a questionnaire code. 


\section{Data collection instrument and technique}

Data were collected by face to face interviews using semi-structured and pre-tested questionnaires. Data collection tools were prepared first in English and translated into local languages (Afaan Oromo and Amharic) then re-translated back to English by another person who was blinded for the English version to check the clarity of the questionnaire. Data collectors were four (4) Master of Science in integrated clinical and community mental health students. One day training on the study objectives, data collection methods, ethical issues, and data collection tools was given for data collectors and the supervisors. The pre-test was conducted on $5 \%$ of the sample. Data collectors were supervised by two Masters of Science students in public health and the principal investigator. On each day of the data collection, the completed questionnaires were checked for completeness and finally, the collected data were entered into a computer and processed.

The questionnaire has the following components: Socio-demographic factors (age, sex, ethnicity, religion, marital status, educational status, occupational status, and monthly income); current substance use (khat, smoking cigarettes and alcohol); medication nonadherence; clinical factors (duration of illness, duration of treatment, history of admission and comorbid physical illness) and World Health Organization Quality of Life Scale-Brief version (WHOQoL-BREF) to assess the quality of life.

WHOQoL-BREF is 26 items self-administered generic questionnaire and it is a short version of the WHO QoL-100 scale [24]. This tool is a sound, cross-culturally valid assessment of QoL [25] and it is found a suitable tool for the assessment of QoL of people with schizophrenia [26]. WHOQOL-BREF was found to have good reliability (a high internal consistency) and validity which grants suitability of the tool for the person with schizophrenia [25]. The tool has four domain scores: physical health (7 items), psychological health (6 items), social relationships (3 items), environmental health domain (8 items) as well as two separately scored items about the individuals' perception of their quality of life (QI) and health (Q2). The scores of each item in each domain were added, in case of negative items (i.e. the response of Q3, Q4, and Q26 was reverse coded); and multiplied by 4 to be directly comparable with WHOQOL-100. Therefore, Domain scores are scaled in a positive direction (i.e. higher scores correspond to a better quality of life). The WHOQoL-BREF scale in this study demonstrated a high internal consistency reliability coefficient (Cronbach's alpha $=0.96)$. Regarding medication nonadherence, it was measured by the 4-item Morisky Medication Adherence Scale (MMAS-4) [27]. It was a self-reported medication-taking behavior scale. It consists of four items with a scoring scheme of Yes $=1$ and $\mathrm{No}=0$. The items in MMAS-4 were summed to give a range of scores from zero to four (0-4). For this study, participants who scored 1 or more were considered as non- adherent while those who scored 0 was taken as adherent. The Cronbach's $\alpha$ in this study was 0.77 . We collected data about current substance use by yes/no questions. Finally data about having the comorbid physical illness was recorded by reviewing their medical records.

\section{Data processing and analysis}

Collected data were checked, coded and entered into EpiData Version 3.1 and then exported to Statistical Package for Social Science Version 25.0 for further analysis. Descriptive statistics, such as frequency, mean and standard deviations were computed to describe the characteristics of the study population. The assumption for linear regression analysis including the presence of a linear relationship between the outcome and predictor variable, the test of normality, collinearity statistics, auto-correlation and homoscedasticity were checked. Bivariate linear regression analysis was done for each independent variable against the dependent variable and variables with $p$-value $<0.25$ were considered as a candidate for multiple linear regression. Finally, multiple linear regression analysis was done to identify factors associated with quality of life. In the final adjusted multiple linear regression, variables with a $P$-value $<0.05$ were declared statistically significantly associated with quality of life. Un-standardized Beta $(\beta)$ coefficients with 95\% confidence interval (CI) were computed to assess the level of association and statistical significance in multiple linear regression analysis.

\section{Data quality control}

The questionnaire used in this study was prepared first in English and translated into local languages (Afaan Oromo and Amharic) then re-translated back to English by another person who was blinded for the English version to check the clarity of questionnaire. In our study, the internal consistency reliability coefficient (Cronbach's alpha) for the WHOQoL-BREF scale was 0.96 and for the 4-item Morisky Medication Adherence Scale (MMAS-4) was 0.77 . One day training was given for data collectors and supervisors. The pre-test was conducted on $5 \%$ of the sample to identify potential problems on data collection tools and to check the consistency of the questionnaire and modification of the questionnaire. Regular supervision and support were given for data collectors by the supervisors and principal investigator to ensure that all necessary data are properly collected. The collected data were checked for completeness and 
consistency by supervisors and principal investigators on a daily bases during the data collection time.

\section{Operational definitions Schizophrenia}

It is a clinical diagnosis reached by the clinician based on DSM-IV/V diagnostic criteria [1].

\section{Medication non-adherence}

Any participant scoring more than 0 by Morisky Medication Adherence Scale (MMAS-4) was considered as non- adherent while those with 0 scores were taken as adherent [20].

\section{Current substance use-}

Using any psychoactive substances at least once during the past 3 months [28].

\section{Ethical consideration}

Ethical clearance was obtained from the Research Ethical Review Board of Jimma University, Institute of health and the study was performed according to the declaration of Helsinki. Written informed consent was obtained from study participants and they were told the right to refuse or discontinue participation at any time they want and the chance to ask anything about the study. After data entry was completed, the questionnaires were kept securely locked.

\section{Results}

Socio-demographic, medication non-adherence, clinical factors and current substance use data of study participants

In this study, the participants' mean age was 33 years (SD 8) with the minimum and maximum age 18 and 54 years respectively. More than half of the study participants were married and $(n=242,68.9 \%)$ were males and $(n=203,57.8 \%)$ were urban residents. Many of them (23.9\%) were farmers followed by government workers (22.5\%). Concerning their educational status, $28.2 \%$ of them attended primary school and followed by those who had no formal education (27.1\%). Regarding their current substance use, 152(43.3\%), 248(70.7\%) and 97(27.6\%) had used tobacco, Khat, and alcohol at least once during the past 3 months respectively. Regarding the medication non-adherence status of the participants, as measured by MMAS-4, of the 351 people with schizophrenia included in this study, 111(31.65\%) were nonadherent to the medications (Table 1).

\section{Perceived quality of life of people with schizophrenia}

In this study, the respondents' mean (SD) score of their overall quality of life was $44.81 \pm 8.87$ and $51.3 \%(n=$ $180)$ and $48.7 \%(n=171)$ of the study participants scored below the mean and above the mean in overall quality of life respectively. The minimum and maximum mean scores of the study participants in overall quality of life were 19 and 63 respectively. Among the four domains of quality of life, respondents scored highest mean in the physical health domain $(12.11 \pm 2.04)$ and scored lowest mean in the social relationship domain $(10.14 \pm 3.12)$ respectively (Table 2).

\section{Quality of life and its association with current substance use, medication non-adherence and clinical factors of people with schizophrenia}

We performed simple and multiple linear regression analyses to identify the association of quality of life with current substance use, medication non-adherence and clinical factors of people with schizophrenia. Quality of life in physical health domain was negatively significantly associated with medication non-adherence (beta $=$ 4.42, $P<0.001)$, who had comorbid physical illness (beta $=-2.74, P<0.001$ ), current tobacco use (beta $=-$ $1.16, P<0.004)$ and current chewing khat (beta $=-1.15$, $P<0.003)$ and the variance of quality of life in physical health domain was explained $40.6 \%$ by all predictors $\left(\mathrm{R}^{2}=0.406, P<0.001\right)$. Quality of life in psychological health domain was negatively significantly associated with medication non-adherence (beta $=-4.49, \quad P<$ 0.001 ), treatment duration (beta $=-0.17, P<0.04$ ), who had comorbid physical illness (beta $=-2.13, P<0.004$ ), current tobacco use (beta $=-1.23, P<0.001$ ) and current chewing khat (beta $=-1.58, P<0.001$ ) and all predictors explain $47.8 \%$ of the variance in the psychological health domain of quality of life (Adjusted R2 $=0.478, P<0.001$ ). The social relationships domain of quality of life was negatively significantly associated with medication nonadherence (beta $=-2.29, P<0.001$ ), treatment duration (beta $=-0.14, P<0.005$ ), who had comorbid physical illness (beta $=-1.25, P<0.007$ ) and current tobacco use (beta $=-0.88, P<0.001$ ), and the predictors explain $39.6 \%$ of the variance in the social relationships of quality of life (Adjusted R2 $=0.396, P<0.001$ ). The environmental health domain of quality of life was negatively significantly associated with medication non-adherence (beta $=-4.95, P<0.001$ ), treatment duration (beta $=-$ $0.24, P<0.02$ ), who had comorbid physical illness (beta $=$ $-3.39, \mathrm{P}<0.001$ ), current tobacco use (beta $=-1.98$, $\mathrm{P}<0.001$ ) and current chewing khat (beta $=-2.63, \mathrm{P}<$ 0.001 ), and the predictors explain $48.1 \%$ of the variance in the environmental health domain of quality of life (Adjusted $\mathrm{R}^{2}=0.481, P<0.001$ ).

In this study, the overall quality of life has significant negative association with medication non-adherance (beta $=-18.1, p<0.001$ ), treatment duration (beta $=$ $0.67, p<0.02$ ), having comorbid physical illness (beta $=$ $-9.9, \mathrm{p}<0.001$ ), current tobacco use (beta $=-5.73, P<$ 
Table 1 Socio-demographic, medication non-adherence, clinical factors and current substance use data of people with schizophrenia $(n=351)$

\begin{tabular}{|c|c|c|c|}
\hline Variables & $\begin{array}{l}\text { Variable } \\
\text { categories }\end{array}$ & Frequency(n) & Percentage(\%) \\
\hline \multirow[t]{2}{*}{ Sex } & Male & 242 & 68.9 \\
\hline & Female & 109 & 31.1 \\
\hline \multirow[t]{4}{*}{ Marital status } & $\begin{array}{l}\text { Never married/ } \\
\text { single }\end{array}$ & 120 & 34.2 \\
\hline & Married & 193 & 55.0 \\
\hline & Divorced & 30 & 8.5 \\
\hline & Widowed & 8 & 2.3 \\
\hline \multirow[t]{3}{*}{ Religion } & Muslim & 228 & 65.0 \\
\hline & $\begin{array}{l}\text { Orthodox } \\
\text { Christian }\end{array}$ & 66 & 18.8 \\
\hline & $\begin{array}{l}\text { Protestant } \\
\text { Christian }\end{array}$ & 57 & 16.2 \\
\hline \multirow[t]{6}{*}{ Ethnicity } & Oromo & 236 & 67.2 \\
\hline & Amhara & 38 & 10.8 \\
\hline & Yem & 6 & 1.7 \\
\hline & Dawuro & 13 & 3.7 \\
\hline & Kaffa & 30 & 8.5 \\
\hline & Other $^{a}$ & 28 & 8.0 \\
\hline \multirow[t]{6}{*}{$\begin{array}{l}\text { Occupational } \\
\text { status }\end{array}$} & $\begin{array}{l}\text { Government } \\
\text { worker }\end{array}$ & 79 & 22.5 \\
\hline & Farmer & 84 & 23.9 \\
\hline & Merchant & 35 & 10.0 \\
\hline & Housewife & 45 & 12.8 \\
\hline & Daily labor & 45 & 12.8 \\
\hline & Students & 63 & 17.9 \\
\hline \multirow[t]{4}{*}{$\begin{array}{l}\text { Educational } \\
\text { status }\end{array}$} & $\begin{array}{l}\text { No formal } \\
\text { education }\end{array}$ & 95 & 27.1 \\
\hline & Primary school & 99 & 28.2 \\
\hline & $\begin{array}{l}\text { Secondary } \\
\text { school }\end{array}$ & 77 & 21.9 \\
\hline & Above secondary & 80 & 22.8 \\
\hline \multirow[t]{2}{*}{ Residence } & Urban & 203 & 57.8 \\
\hline & Rural & 148 & 42.2 \\
\hline \multirow[t]{2}{*}{ Age } & $<=33$ & 179 & 51.0 \\
\hline & $>33$ & 172 & 49.0 \\
\hline \multirow{2}{*}{$\begin{array}{l}\text { Current tobacco } \\
\text { use }\end{array}$} & No & 199 & 56.7 \\
\hline & Yes & 152 & 43.3 \\
\hline \multirow{2}{*}{$\begin{array}{l}\text { Current alcohol } \\
\text { use }\end{array}$} & No & 254 & 72.4 \\
\hline & Yes & 97 & 27.6 \\
\hline \multirow{2}{*}{$\begin{array}{l}\text { Current chewing } \\
\text { khat }\end{array}$} & No & 103 & 29.3 \\
\hline & Yes & 248 & 70.7 \\
\hline \multirow{2}{*}{$\begin{array}{l}\text { Medication adherence } \\
\text { status }\end{array}$} & Adherent & 240 & 68.4 \\
\hline & Non-adherent & 111 & 31.65 \\
\hline Have admission & No & 201 & 57.3 \\
\hline
\end{tabular}

Table 1 Socio-demographic, medication non-adherence, clinical factors and current substance use data of people with schizophrenia $(n=351)$ (Continued)

\begin{tabular}{llll}
\hline Variables & $\begin{array}{l}\text { Variable } \\
\text { categories }\end{array}$ & Frequency(n) & Percentage(\%) \\
\hline history & Yes & 150 & 42.7 \\
Have a comorbid & No & 331 & 94.3 \\
physical illness & Yes & 20 & 5.7 \\
IIIness duration & $<5$ year & 141 & 40.2 \\
& 5-9year & 158 & 45.0 \\
Treatment duration & 3- < 6 months & 25 & 14.8 \\
& 6 month- 5 year & 154 & 4.1 \\
& $\geq 5$ year & 172 & 49.9 \\
\hline
\end{tabular}

Other ${ }^{\mathrm{a}}$ - Tigre, Walayta

0.001 ) and current chewing khat (beta $=-6.22, \mathrm{P}<$ 0.001 ) and the predictors explained $53.3 \%$ of the variance in the overall quality of life (Adjusted $R^{2}=0.533$, $\mathrm{P}<0.001$ ) (Table 3).

\section{Discussion}

The current study aimed to investigate the quality of life and its association with medication non-adherence, current substance use and clinical factors of people with schizophrenia attending follow up service at Jimma University Medical Center, psychiatry clinic, Southwest Ethiopia. This study was the first study in Ethiopia to investigate the association of medication non-adherence and substance use with the quality of life of people with schizophrenia. In this study, the participants' mean score of overall quality of life was found to be $(44.81 \pm 8.87)$ and the domain with the lowest mean score was the social relationships domain $(10.14 \pm 3.12)$.

In our study, the $111(31.65 \%)$ of participants were non-adherent to their medication and this result was higher than study conducted at Ayder Referral Hospital, Mekelle, Northern Ethiopia which revealed $26.5 \%$ of patients with schizophrenia were non-adherent to their antipsychotic medication [29] and the result was lower than finding of the study conducted at Bahir Dar Felege Hiwote Referral hospital, northwest Ethiopia which revealed overall prevalence of medication non-adherence was $55.2 \%$ [30] This difference could be due to the different tools used to measure medication non-adherence. The lowest score on the social relationship domain of QoL among people with schizophrenia in our study could be due to the negative symptoms, which affect the patient's ability to live independently, to perform activities of daily living, to be socially active and maintain personal relationships. Also, it could be due to the stigma towards mental illness, which excludes the mentally ill from social life (21). 
Table 2 Mean (SD) scores of quality of life among people with schizophrenia $(n=351)$

\begin{tabular}{llll}
\hline Domains & Mean $( \pm$ SD $)$ & Range \\
\cline { 3 - 4 } & & Minimum & Maximum \\
\hline Physical Health & $12.11 \pm 2.0$ & 4 & 19 \\
Psychological Health & $11.14 \pm 2.26$ & 5 & 17 \\
Social Relationships & $10.14 \pm 3.12$ & 4 & 20 \\
Environmental Health & $11.42 \pm 2.60$ & 5 & 17 \\
Overall Quality of life & $44.81 \pm 8.87$ & 19 & 63 \\
\hline
\end{tabular}

In the current study, medication non-adherence was significantly and negatively associated with all domains of quality of life and with the overall quality of life, and this result was in line with the previous study [20]. This finding indicates that medication adherence plays a key role in the quality of life of people with schizophrenia and improving medication adherence is a good approach to improve the quality of life of people with schizophrenia.

In our study, regarding the association between quality of life and clinical factors, treatment duration has a significant negative association with psychological domain, social relationships, environmental domain and overall quality of life. The possible justification behind this finding will be as reported in the previous study, treatment duration and illness duration have a significant association with medication non-adherence among people with schizophrenia [31] and as explained in the current study, medication non-adherence has a significant negative association with participants' quality of life. Because of this, the treatment duration of people with schizophrenia could affect their quality of life by affecting medication adherence. In our study also, having the comorbid physical illness was significantly negatively associated with a physical domain, psychological domain, social relationships, environmental health domain and overall quality of life and this result is supported by the previous study which revealed people with schizophrenia alone had a better QoL than those with any multimorbidity [32]. This finding indicates that early detection and treatment of comorbid physical illness among people with schizophrenia will have significant importance to improve their overall quality of life.

This study result also revealed current tobacco use has significant negative association with all domains of quality of life including physical health, psychological health, social relationships, and environmental health domains as well as with overall quality of life and the current chewing khat has significant negative association with physical, psychological, environmental domains and overall quality of life. This finding was in line with the previous study results which revealed that schizophrenic patients with substance use disorder comorbidity would report poorer QoL scores than non-comorbid patients $[17,33]$. There are different possible justifications why patients with schizophrenia and comorbid substance use have poorer QoL scores. These justifications include: Patients with comorbid substance use would have poor interpersonal relationships than non-substance-using patients. Because these patients could spend their time searching and using substances [1]. Again substance use, especially during either intoxication or withdrawal time, could cause behavioral change and even it could directly worse psychiatric symptoms and could affect their psychological health besides social relationships. Substance use can also affect their coping skills with illness by making them non-compliance to the treatments [1].

Our study was not without limitations. The WHOQoL-BREF scale of Quality of Life measures only capture of a small point of time (in the last 2 weeks) in the patients' life and it is difficult to generalize to patients overall QoL. Due to its cross-sectional nature, the study could not explore the cause and effect relationships of variables. Questions about substance use are

Table 3 Multiple linear regression analysis of quality of life with medication non-adherence, current substance use and clinical factors of people with schizophrenia $(n=351)$

\begin{tabular}{|c|c|c|c|c|c|c|c|c|c|c|}
\hline \multirow[b]{2}{*}{ Variables } & \multicolumn{2}{|c|}{ Physical Health } & \multicolumn{2}{|c|}{ Psychological Health } & \multicolumn{2}{|c|}{ Social Relationships } & \multicolumn{2}{|c|}{ Environmental Health } & \multicolumn{2}{|c|}{ Overall quality of life } \\
\hline & Beta & $P$ & Beta & $P$ & Beta & $P$ & Beta & $P$ & Beta & $P$ \\
\hline Medication non-adherence & -4.42 & 0.001 & -4.49 & 0.001 & -2.29 & 0.001 & -4.95 & 0.001 & -18.1 & 0.001 \\
\hline Illness duration & 0.01 & 0.87 & 0.03 & 0.75 & 0.07 & 0.15 & 0.07 & 0.49 & 0.15 & 0.6 \\
\hline Rx duration & -0.13 & 0.12 & -0.17 & 0.04 & -0.14 & 0.005 & -0.24 & 0.02 & -0.67 & 0.02 \\
\hline Have admission history & -0.46 & 0.22 & -0.41 & 0.24 & -0.11 & 0.62 & -0.60 & 0.18 & -1.8 & 0.15 \\
\hline Have a comorbid physical illness & -2.74 & 0.001 & -2.13 & 0.004 & -1.25 & 0.007 & -3.39 & 0.001 & -9.9 & 0.001 \\
\hline Current tobacco use & -1.16 & 0.004 & -1.23 & 0.001 & -0.88 & 0.001 & -1.98 & 0.001 & -5.73 & 0.001 \\
\hline Current chewing khat & -1.15 & 0.003 & -1.58 & 0.001 & -0.39 & 0.10 & -2.63 & 0.001 & -6.22 & 0.001 \\
\hline Current alcohol use & -0.12 & 0.75 & 0.52 & 0.09 & -0.26 & 0.27 & 0.71 & 0.14 & 0.74 & 0.55 \\
\hline
\end{tabular}


sensitive by nature and there might be underreporting of using substances.

\section{Conclusions}

In our study, the social relationship domain of quality of life of people with schizophrenia has the lowest mean score. Medication non-adherence, current tobacco use, current chewing khat, treatment duration, and having comorbid physical illness were found to have a statistically significant association with the overall quality of life of people with schizophrenia. This study recommends that all stakeholders including the health professionals who are treating people with schizophrenia should have to give priority for interventions that improve their social deficits and medication adherence, screen and treat for their comorbid physical illness and decreasing substance abuse is imperative.

\section{Abbreviations}

DSM-IVN: Diagnostic and Statistical Manual of Mental Disorders, Version IVNi JUMC: Jimma University Medical Center; OPD: Outpatient Department; QoL: Quality of Life; WHO: World Health Organization; WHOQOL-BREF: World Health Organization Quality of Life Assessment Short version

\section{Acknowledgments}

We would like to acknowledge Jimma University, Institute of Health for financial support during data collection and providing us ethical clearance. Again we would like to thank the study participants, data collectors, and supervisors.

\section{Authors' contribution}

DD wrote the protocol, design the study, organized the data collection process, analyzed the data and reviewing and editing the manuscript. SG revise and approve the protocol, participated in data analysis, reviewing and editing the manuscript. TA contributed to the analysis of the data, drafting the manuscript, critically reviewed and approved the manuscript for publication. All authors read and approved the final manuscript.

\section{Funding}

The study was financially supported by Jimma University, Institute of health during data collection but the University has no role in the publication process.

\section{Availability of data and materials}

The datasets used and/or analyzed during the current study are available from the corresponding author on reasonable request by tilahunabdeta@gmail.com

\section{Ethics approval and consent to participate}

The project was ethically approved by the Research Ethical Review Board of Jimma University, Institute of health. Written informed consent was obtained from all participants. Confidentiality was kept and no personal identifiers were recorded.

\section{Consent for publication}

Not applicable.

\section{Competing interests}

The authors have declared that they have no conflicts of interest.

\section{Author details}

${ }^{1}$ Department of Psychiatry, Faculty of health and medical sciences, Mettu University, Mettu, Ethiopia. ${ }^{2}$ Department of Psychiatry, Institute of health, Jimma University, Jimma, Ethiopia. ${ }^{3}$ Department of Psychiatry, college of health and medical sciences, School of Nursing and Midwifery, Haramaya University, Harar, Ethiopia.
Received: 16 October 2019 Accepted: 23 March 2020

Published online: 30 March 2020

\section{References}

1. Kaplan BJ. Kaplan and Sadock's synopsis of psychiatry. Behavioral sciences/ clinical psychiatry. Tijdschrift Voor Psychiatrie. 2016;58(1):78-9.

2. Solanki RK, et al. Schizophrenia: impact on the quality of life. Indian J Psychiatry. 2008;50(3):181.

3. Kessler RC, et al. The global burden of mental disorders: an update from the WHO world mental health (WMH) surveys. Epidemiol Psychiatric Sci. 2009; 18(1):23-33.

4. Ayano G. Schizophrenia: a concise overview of etiology epidemiology diagnosis and management: a review of the literature. J Schizophrenia Res. 2016;3(2):2-7.

5. Isaac M, Chand P, Murthy P. Schizophrenia outcome measures in the wider international community. Br J Psychiatry. 2007;191(S50):s71-7.

6. Fekadu A, Thornicroft G. Global mental health: perspectives from Ethiopia. Glob Health Action. 2014;7(1):25447.

7. Association, A.P. Diagnostic and statistical manual of mental disorders. BMC Med. 2013;17:133-7.

8. Pitkänen A. Improving the quality of life of patients with schizophrenia in acute psychiatric wards; 2010.

9. Narvaez JM, et al. Subjective and objective quality of life in schizophrenia. Schizophr Res. 2008;98(1-3):201-8.

10. Group, W. The World Health Organization quality of life assessment (WHOQOL): position paper from the World Health Organization. Soc Sci Med. 1995;41(10):1403-9.

11. Li Y, et al. Quality of life in Chinese patients with schizophrenia treated in primary care. Psychiatry Res. 2017;254:80-4.

12. Bokhari $\mathrm{SQ}$, et al. Correlation between quality of life and positive and negative symptoms of schizophrenia. Pak J Med Health Sci. 2015;9(1):367-70.

13. Bobes J, et al. Quality of life in schizophrenic patients. Dialogues Clin Neurosci. 2007;9(2):215.

14. de Oliveira MF, et al. Ways to measuring quality of life in mental health. Int Arch Med. 2015;8(91). https://doi.org/10.3823/1690.

15. Mahmud MHS, Yeasmin B, Mandal S. Quality of life of schizophrenic patients in a tertiary care hospital in Bangladesh. Bangladesh J Psychiatry. 2015:29(1):30-4.

16. Hamaideh S, et al. Quality of life, social support, and severity of psychiatric symptoms in J Jordanian patients with schizophrenia. J Psychiatr Ment Health Nurs. 2014;21(5):455-65.

17. Aras HI, Yazar MS, Altinbas K. Quality of life among dually diagnosed and non-substance-using male schizophrenia outpatients. S Afr J Psychiatry. 2013;19(2):35-9.

18. Bengtsson-Tops A, Hansson L. Subjective quality of life in schizophrenic patients living in the community. Relationship to clinical and social characteristics. Eur Psychiatry. 1999:14(5):256-63.

19. Hayhurst $K$, et al. Improved quality of life over one year is associated with improved adherence in patients with schizophrenia. Eur Psychiatry. 2014; 29(3):191-6.

20. Adelufosi $\mathrm{AO}$, et al. Medication adherence and quality of life among Nigerian outpatients with schizophrenia. Gen Hosp Psychiatry. 2012; 34(1):72-9.

21. Ogunnubi OP, et al. Medication adherence among Nigerians with schizophrenia: correlation between clinico-demographic factors and quality of life. Ment IIIn. 2017;9(6889). https://doi.org/10.4081/mi.2017.6889.

22. Herman M. Neurocognitive functioning and quality of life among dually diagnosed and non-substance abusing schizophrenia inpatients. Int J Ment Health Nurs. 2004;13(4):282-91.

23. Derajew $\mathrm{H}$, et al. Prevalence of depression and its associated factors among primary caregivers of patients with severe mental illness in the southwest, Ethiopia. BMC Psychiatry. 2017;17(1):88.

24. World Health Organization. Programme on mental health: WHOQOL user manual, 2012 revision. World Health Organization. 1998. https://apps.who. int/iris/handle/10665/77932.

25. Skevington SM, Lotfy M, O'Connell K. The World Health Organization's WHOQOL-BREF quality of life assessment: psychometric properties and results of the international field trial. A report from the WHOQOL group. Qual Life Res. 2004;13(2):299-310.

26. Mas-Expósito L, et al. The World Health Organization quality of life scale brief version: a validation study in patients with schizophrenia. Qual Life Res. 2011;20(7):1079-89. 
27. Morisky DE, Green LW, Levine DM. Concurrent and predictive validity of a self-reported measure of medication adherence. Med Care. 1986;24(1):6774.

28. Phinney R, et al. Lifetime and Annual Substance Use, Abuse, and Dependence among Current and Former Welfare Recipients. Ann Arbor: University of Michigan Gerald R. Ford School of Public Policy. http://www. fordschool.umich.edu/research/poverty/pdf/WES-SubstanceUse.pdf; 2005.

29. Eticha $\mathrm{T}$, et al. Factors associated with medication adherence among patients with schizophrenia in Mekelle, Northern Ethiopia. PLoS One. 2015 10(3):e0120560. https://doi.org/10.1371/journal.pone.0120560.

30. Gebeyehu DA, et al. Psychotropic medication non-adherence among patients with severe mental disorder attending at Bahir Dar Felege Hiwote referral hospital, Northwest Ethiopia, 2017. BMC Res Notes. 2019;12(1):102.

31. Lacro JP, et al. Prevalence of and risk factors for medication nonadherence in patients with schizophrenia: a comprehensive review of recent literature. J Clin Psychiatry. 2002;63(10):892-909.

32. Bhalla IP, Stefanovics EA, Rosenheck RA. Mental health multimorbidity and poor quality of life in patients with schizophrenia. Schizophr Res. 2018;201: 39-45.

33. Duke PJ, et al. Comorbid non-alcohol substance misuse among people with schizophrenia: an epidemiological study in Central London. Br J Psychiatry. 2001:179(6):509-13.

\section{Publisher's Note}

Springer Nature remains neutral with regard to jurisdictional claims in published maps and institutional affiliations.

Ready to submit your research? Choose BMC and benefit from:

- fast, convenient online submission

- thorough peer review by experienced researchers in your field

- rapid publication on acceptance

- support for research data, including large and complex data types

- gold Open Access which fosters wider collaboration and increased citations

- maximum visibility for your research: over $100 \mathrm{M}$ website views per year

At BMC, research is always in progress.

Learn more biomedcentral.com/submissions 